\title{
Surfaces
}

\section{On Translatability}

Wolfgang Iser

\section{Volume 4, 1994}

CONFÉRENCE INTERNATIONALE SUR LE DISCOURS HUMANISTE (PREMIÈRE RENCONTRE, 3-8 AVRIL, 1994)

INTERNATIONAL CONFERENCE ON HUMANISTIC DISCOURSE (FIRST MEETING, APRIL 3-8, 1994)

URI : https://id.erudit.org/iderudit/1064971ar

DOI : https://doi.org/10.7202/1064971ar

Aller au sommaire du numéro

\section{Éditeur(s)}

Les Presses de l’Université de Montréal

\section{ISSN}

1188-2492 (imprimé)

1200-5320 (numérique)

Découvrir la revue

Citer cet article

Iser, W. (1994). On Translatability. Surfaces, 4. https://doi.org/10.7202/1064971ar
Résumé de l'article

Considérant l'élaboration de la notion de " traduisibilité » essentielle à l'étude des rencontres entre les cultures et des interactions intra-culturelles, l'auteur définit la " traduisibilité " comme " une traduction de l'altérité qui ne subsume pas cette dernière sous des notions préconçues » et propose de concevoir celle-ci selon un modèle cybernétique basé sur le phénomène de la boucle récurrente.
Copyright (C) Wolfgang Iser, 1994

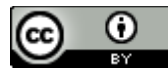

Ce document est protégé par la loi sur le droit d'auteur. L'utilisation des services d'Érudit (y compris la reproduction) est assujettie à sa politique d'utilisation que vous pouvez consulter en ligne.

https://apropos.erudit.org/fr/usagers/politique-dutilisation/ 
On Translatability

\title{
Wolfgang Iser
}

\begin{abstract}
This essay addresses the question of translatability as a key concept for understanding encounters between cultures and interactions within cultures. In this view, translatability implies translation of otherness without subsuming it under preconceived notions. In conclusion, this essay proposes a cybernetic model of cultural understanding based on recursive looping.
\end{abstract}

\section{RÉSUMÉ}

Considérant l'élaboration de la notion de $<<$ traduisibilité $>>$ essentielle à l'étude des rencontres entre les cultures et des interactions intra-culturelles, l'auteur définit la $<<$ traduisibilité>> comme $<<$ une traduction de l'altérité qui ne subsume pas cette dernière sous des notions préconçues $>>$ et propose de concevoir celle-ci selon un modèle cybernétique basé sur le phénomène de la boucle récurrente.

The following remarks are aimed at exploring the notion of translatability in order to find out why this has become an issue not only in the manifold operations of our day-to-day living, but also in relation to what has become a prime concern of the humanities : i.e. cultural studies. What could be the reason for elevating translatability into a key-concept for the encounter between cultures or the interaction between intracultural levels? Is translatability more than a metaphor for cultural exchange, and if so, to what extent is it possible to assess the range covered by such a concept? 
We usually associate translation with converting one language into another, be it foreign, technical, professional, or otherwise. Nowadays, however, not only languages have to be translated. In a rapidly shrinking world, many different cultures have come into close contact with one another, calling for a mutual understanding not only in terms of the culture to which one belongs, but also in terms of the specificity pertaining to the culture encountered. The more the latter becomes the case, the more a kind of translation is bound to occur, as the specificity of the culture encountered can be grasped only when projected onto what is familiar. In this respect a foreign culture is not simply subsumed under one's own frame of reference; instead, the very frame is subjected to alterations in order to accommodate what does not fit. Such a transposition runs counter to the idea of the hegemony of one culture over the other, and hence the notion of translatability emerges as a counter-concept to a mutual superimposing of cultures.

Furthermore, even a culture is not a monolithic entity; it rather appears to be a multi-layered phenomenon in that it consists of diversified levels dubbed as high culture, low culture, sub-culture, and counter-culture -- all of which map out a cultural realm. Levels of culture depend upon one another and can be ascertained for what they are through mutual spotlighting, thereby throwing each other into relief in a way that makes them reveal their distinctive features. The various levels may be just as alien to one another as different cultures are, and thus can be equally distinguished from one another by their varying degrees of strangeness. Again, the issue of translatability gains prominence, as the various levels appear to be /pp. 5-6/ mutually exclusive and yet provide stances for looking at and assessing one another. These levels, then, turn into mirrors for one another, and their mutual refraction translates each level as a figure into the ground of the other one. In this respect, translatability proves to be a counter-concept to the otherwise prevailing idea of cultural hierarchy.

Translatability seems to be all the more necessary in a multicultural society as there is a struggle for dominance to be observed in such a society. Although translatability may not be a mighty force in itself, it can trigger the attempt to counteract political power, which the various groups in such a social set-up bring to bear in order to impose their own cultural heritage upon other segments in a multicultural community. However, translatability exposes the politics operative in such a struggle for dominance, and thus proves to be a counter-concept to both the politics inherent in culture and the politicizing of culture as a whole.

Translatability aims at comprehension, whereas encounters between cultures or interactions between levels of culture involve either assimilation or appropriation by making inroads into one another, trying to get out of a different culture or the different intra-cultural levels what seems attractive, useful, or what has to be combated and suppressed for whatever reasons.

Moreover, the idea of translatability marks a break with what has come to be known as comparative culture, not least because the expected achievements of comparative culture are not very promising, if not altogether poor. This in 
itself is not a surprise. If comparison is to be elevated to the be-all and endall of cultural studies, the question arises whether it is more than just an empty category, for comparison moves into focus only the differences and similarities of the cultures scrutinized. And what is worse, comparison poses as a transcendental stance or at least as a vantage point for evaluating the cultures being compared without being able to substantiate any of the evaluations provided, since the comparison in itself does not contain a set of values. What deserves to be noted, however, is the fact that comparison is definitely a rudimentary though abortive attempt at devising a cross-cultural discourse, borne out by the fact that it is not an integral part of the cultures compared, thus serving as a link that does not pertain to them.

Obviously, cultural studies are bound to devise a cross-cultural discourse of which comparison is at best a most elementary paradigm. Comparison fails to address two vital questions : a) why should cultures be compared, a question that is never satisfactorily answered; and b) why is the comparison hardly ever subjected to close scrutiny, in consequence of which the presuppositions that govern the comparison remain unexamined.

What might be considered as a remedy to these shortcomings is the growing endeavor in cultural studies to draft frames for cultural typologies or even a typology of cultures. A cultural typology allows for basically two different approaches, which more often than not have to be combined in order to become effective. There is a need to define the criteria that make up a type, and there is equally a need to assess the shifts to be observed in a typologically conceived culture.

In the pursuit of such an approach, a culture is broken down into various components considered to be integral to a cultural type, such as religious observances, forms of government, organization of agriculture and industry, the range of the arts. Even if this list of prominent constituents of a cultural type can be extended, there are hardly any guidelines that allow us to decide how many of these components are necessary in order to obtain a full-fledged cultural type.

Such a deficiency calls for compensation usually provided by umbrella concepts such as evolution and change, which the cultural types either undergo or are subjected to. The question, however, remains whether there is a pattern to be discerned that governs the evolution to be observed. Is there a telos or at least a structure which energizes the drive for change, or are there more factors to be ascertained that guide such an evolution? It may suffice to mention only two opposing views concerning the constituents of a cultural typology. Levi-Strauss considers the binary opposition derived from structural linguistics as a blueprint of cultural types that are resistant to change. Eric Gans, on the other hand, postulates an "originary scene" for which "such activities as hunting generate plausible settings," and in which "fear of conflict is the sole necessary motivation for the abortion of the original gesture of appropriation." [1] Vis-à-vis the killed animal a ritual has to be imposed, so that the huntsmen do not kill each other in deciding who gets the prey. Rituals of that kind provide the pattern for the emergence of culture as continuous self-differentiation. 
Irrespective of what one may be inclined to favor, each of these explanations at least allows for developing a cross-cultural discourse, in which either a permanent structure or a self-propelled differentiation forms the guidelines. These guidelines are more sophisticated than the mere comparison of cultures, which at best indicates the necessity of a cross-cultural discourse.

In contradistinction to the explanations provided for the rise of culture, the life of cultures proceeds in mutual appropriation, assimilation, exploitation, interpenetration, and superimposition. Such a mutuality is an inalienable component of the encounter between cultures, and hence calls for establishing a cross-cultural discourse different from the ones touched upon so far. What has become pertinent is an assessment of cross-cultural relationships. Such an effort is apposite, not least as the cross-cultural relations seem to be guided by a great many different intentions -- all of which, however, appear to be modes of translation : whether one culture translates itself according to its own terms into another one, or whether it tries to comprehend a foreign culture in terms that are basic to the culture concerned. Thus translatability turns out to be the hallmark of any crosscultural interchange and -- to mention it only in passing -- for the mutual interpenetration of the media as well. Furthermore, the issue of translatability promises to rid us of the two bugbears that beset cultural studies these days : a) what is culture; and b) what makes a culture. Instead, translatability makes us focus on the space between cultures.

Such a change of perspective entails a further advantage : a culture -- so it seems -- obtains its salient features not least by demarcating itself from what it is not. Even if we have to bear in mind that the space between cultures does not exactly constitute the specificity of the cultures concerned, it nevertheless allows at least for a mutual mirroring of different cultures. This is due to the fact that the space between does not belong to any of the cultures that refract one another. This makes the space between turn into a condition for self-reflexivity, which can only result in a heightened selfawareness of a culture that sees itself refracted in the mirror of the one encountered. Moreover, such an opportunity permits a stepping out of the very culture one is otherwise so inextricably caught up in, and a distancing from oneself becomes all the more necessary in a shrinking world in which different cultures keep encountering one another.

In this respect, the space between opens up the experience of otherness -currently a key-concept in cultural studies, although hardly fine-tuned beyond its psychoanalytical or political conceptualizations, which in themselves are more often than not forms of domesticating the other. Otherness is by no means an abstract notion, but it becomes tangible only in individual manifestations. It is, therefore, impossible to run the gamut of all conceivable manifestations of otherness, but we can at least illustrate what a differentiation of otherness implies :

Encountering the other awakens awareness of a duality which results in an experience of difference; 
bracketing, suspending, or even excluding the other allows for an exploration of difference that raises the question of why there are such disparities;

incorporating the other aims at assimilation, which leads to a politics of cultural relationships;

appropriating the other highlights goals of utilization that are meant to remedy existing deficiencies;

reflecting oneself in the other entails heightened self-awareness, which leads to self-confrontation;

recognizing the other as primordial generates a call to responsibility prior to any possible knowledge of the other, and may produce an ethics based on imponderable commitment.

The various modes in which otherness manifests itself are already modes of translation. There is no otherness without such modes through which it becomes operative. Consequently, the space between cultures appears to be dually coded : it is both an indication of and a catalyst for translating otherness. Otherness is never to be ascertained in and of itself; instead, it is always present in specific forms of manifestation.

Such a state of affairs implies that otherness cannot be grasped prior to its manifestation through which it becomes tangible. It further highlights that otherness is never identical to itself, but is always other, translating itself into ever other manifestations. This changeability, however, is not independent of the manner in which otherness is encountered. In the case of a mutual confrontation of cultures, the emerging otherness, if it is not assimilated or appropriated, necessitates a translation which -- contrary to comparative culture, typologies of culture, or even conceptualizations of culture -- is not governed by an overarching frame of reference, and yet has to organize a mutual transfer. Translation of otherness is primarily concerned with giving otherness its due without subsuming it under preconceived notions. Such an attempt highlights translatability as an operational mode, which marks it off from the underlying assumptions that guide both comparative culture and typologies of culture.

Translatability, however, requires construing a discourse that allows for transposing a foreign culture into one's own. Such a discourse has to negotiate the space between foreignness and familiarity, which is in the nature of a "black box" that defies explanation. The "black box," in Gregory Bateson's words, reflects the point at which we are "to stop trying to explain things at a certain point."[2] Therefore, the operational mode of a crosscultural discourse can neither explain nor represent anything any more, but has to pivot around such a "black box" which separates cultures from one another.

In order to become fully operative, however, such a discourse must in itself contain a "black box" which not only reflects what is to be negotiated, but which, as inexplicable, energizes its operational drive. Coming to grips with 
an otherness hardly to be known requires a continual looping from the known to the unknown in order to make the unknown fold back upon what is familiar. Hence the mode of such a discourse is one of recursive looping. It develops as an interchange between output and input, in the course of which a familiar projection is corrected insofar as it failed to square with what it has targeted. Consequently, a dual correction occurs : the feed forward returns as an altered feedback loop which, in turn, feeds into a revised output. Recursive looping adjusts future projections to past performances (Wiener). For a foreign culture to become comprehensible, a change of attitude toward the familiar one now being penetrated by something other is unavoidable. The recursive looping organizes such a transfer by processsing the information received, which is to be gauged by the correction of what the output was meant to achieve. Such a recursion is intensified by the fact that each output, in cybernetical terms, is an intervention into the organization of the system targeted, and such inroads bounce back as a heightened complexity of information. Heightened complexity increases the rapidity of self-correction, which results in a fine-tuning of further outputs. Cybernetics distinguishes between positive and negative feedback loops. A negative feedback loop entails that the discrepancy of information between output and input is minimal, and thus serves to stabilize the system which initiated the recursion. A positive feedback loop has far-reaching repercussions on the system that triggered the recursion. It may change the original targets as well as aims, and will tend to unbalance the system concerned by bombarding it with uncontrollable events, thus becoming unable to process adequately the received information for fine-tuning further outputs.

Both types of recursion mark the extremes between which a cybernetically structured cross-cultural discourse operates. This discourse largely depends on its aims, which make it veer to either pole. If the recursive looping is meant to chart a foreign culture up to the point of permitting manageability of what is foreign, then a lot of information generated by the recursion will be screened off. If a grasping of otherness is predominant, then a positive feedback loop will inform the operations. Whatever the direction will be, recursive looping as the mechanics of a cross-cultural discourse allows for a mutual translatability of cultures, which by far outstrips cross-cultural interchange in terms of assimilation, appropriation, and incorporation.

Why is the mechanics of recursive looping an adequate operational mode for translating cultures into one another? It is appropriate insofar as it tallies with what one might consider the make-up of culture. Straightforwardly we may say : a culture is an autopoetic system that continually generates its organizations as well as the shifts occuring in such a self-generated organization. In terms of general systems theory, a culture could be described as a network of interlinking processes which, in turn, produce the very components that set the process in motion. The relationship between process and components is one of a continual recursive looping, in the course of which components structure a process, and the latter yields further components that are fed back into such a network through which a culture gains its salience or even its identity. If a culture is conceived as an autopoetic system that generates its own organization, then a cybernetically operating cross-cultural discourse is a direct offshoot of the ongoing self- 
organization of cultures. Any other type of discourse would bring the life of a culture to a grinding halt.

Furthermore, the mutual translation of cultures by means of a recursive looping brings about comprehension. Such a comprehension is a product arising out of a performance, and not something depending on a transcendental stance, which by definition is outside the cultures to be interlinked. A transcendental stance only allows predication, whereas recursive looping issues into production. In negotiating the space between cultures recursive looping duplicates the intracultural recursions, thus operating always inside of what it tries to make translatable.

There is no longer any overarching third dimension from which to predicate what cross-cultural relationships are like, let alone have to be. Consequently, transcendental stances have to be replaced by an operational mode that works inside of what is to be grasped. Therefore to assess or even to conceptualize cross-cultural relationships from any outside vantage point will only result in subsuming cultural differences under preexisting umbrella concepts, whereas the differences existing have to be acted out.

Thus any kind of thirdness can be exposed for what it is : an interestgoverned stance, more often than not only thinly veiled when pronouncements about cross-cultural relationships are made. Recursive looping, then, may be a chance for restructuring the mechanics of the humanistic discourse which might have repercussions both on the business of interpretation and on the many oppositional discourses, when the realm of cultural studies gets charted.

\section{Wolfgang Iser}

Philosophische Fakultät

Fachgruppe Literaturwissenschaft

Universität Konstanz

Surface Page d'Acceuil/Home Page

[1]Eric Gans, The End of Culture. Toward a Generative Anthropology (Berkeley and Los Angeles, 1985): 20.

[2]Gregory Bateson, Steps to an Ecology of Mind (New York : Ballantine Books, 1972): $39 \mathrm{f}$. 